\title{
Simulasi Kontrol 2 Pompa Supplay Air Bersih Menggunakan Relay Change Over dan Floatless Level Switch (Sebagai Modul Praktek Mahasiswa PS Teknik Pendingin dan Tata Udara)
}

\author{
Sudirman $^{1^{*}}$, I Nyoman Gede Baliarta ${ }^{2}$ \\ ${ }^{1,2}$ Jurusan Teknik Mesin Politeknik Negeri Bali \\ *E-mail: dirmansdr@pnb.ac.id
}

\begin{abstract}
System of water supply pump must be installed in a building. The purpose of this research is to create the practical module for system of water supply pump for building. So the students' competence on the utility of the building, especially in the field of water supply pump system can be achieved more easily. This practice module uses 2 pumps, 2 water tanks, 1 as tank as underground tank and 1 again as tower tank. Using WLC (water level control) to control on-off the pump, based on the water level in the tower tank. Using Relay Change over to automatically convert the pump on duty. In addition it helps to control the water reservoir automatically and maintain the stability of the water distribution in the tower tank.
\end{abstract}

Key words: underground tank, tower tank, water level control, relay change over

\begin{abstract}
ABSTRAK
Sistem supplay air bersih pasti ada dipasang disuatu gedung. Tujuan dari penelitian ini adalah untuk menciptakan modul praktek mahasiswa Program Studi Teknik Pendingin dalam mata Kuliah Praktek Utility Gedung dan BAS. Sehingga kompetensi mahasiswa tentang utility gedung, khususnya dibidang system pompa supplai air bersih bisa tercapai dengan lebih mudah. Modul praktek ini menggunakan 2 buah pompa, 2 buah tangki air, 1 sebagai tangki sebagai tangki underground tank dan 1 lagi sebagai tower tank. Menggunakan WLC (water level control) untuk mengontrol hidup mati pompa berdasarkan level air pada tangki tower. Dan menggunakan Relay Change over untuk merubah pompa on duty secara otomatis. Hasil uji kerja alat simulasi ini, saat level air pada tangki tower low level, Pompa 1 akan hidup sampai level air mencapai upper level dan akan Off, secara otomatis Relay change over merubah pompa on duty dari Pompa 1 ke Pompa 2. Pada saat level air mencapai low level lagi di tangki tower, yang hidup adalah Pompa 2.
\end{abstract}

Kata kunci: underground tank, tower tank,water level control, relay change over

\section{PENDAHULUAN}

Pompa digunakan untuk memindahkan fluida cair dari satu tempat yang lebih rendah ketempat yang lebih tinggi, seperti dalam supplai air bersih dalam gedung. Sedangkan fungsi yang lain adalah untuk mensirkulasikan fluida cair, seperti dalam sebuah sistem kolam renang

Pada sistem sirkulasi air kolam renang hotel, menggunakan pompa lebih dari satu pompa. Karena air kolam harus terus bersirkulasi terus untuk menjaga kondisi air kolam selalu dalam kondisi jernih dan terbebas dari kotoran. Jika hanya satu pompa terpasang dan terjadi kerusakan yang memerlukan waktu lama, hal tersebut akan berdampak buruk terhadap image hotel tersebut. Karena kolamnya tidak bisa digunakan oleh Tamu. Sistem supplai air bersih dalam gedung menggunakan lebih dari satu pompa untuk menjaga kebutuhan air bersih tetap terpenuhi untuk penghuni dalam gedung, menghindari kegagalan sistem memenuhi kebutuhan penghuni air bersih, jika terjadi kerusakan padasalah satu pompa. Pompa bergantian beroperasi berdasarkan sistem kontrol yang dibuat dan dibutuhkan.

PS Teknik Pendingin dan Tata Udara Jurusan Teknik Mesin melengkapi mahasiswa mahasiswa dengan mata kuliah praktek Utility Gedung dan BAS (Building Automation System). Salah satu utility gedung adalah system supplay air bersih.

Kegiatan penelitian ini bertujuan untuk mengembangkan alat-alat praktek yang ada di Lab. Instrumentasi dan Kontrol, khususnya alat praktek Mata Kuliah Praktek Utility Gedung dan BAS, terutama untuk sub praktek utility 
supplay air bersih ke Gedung, serta bahan ajar praktek untuk praktek supplay air bersih ke gedung.

Modul praktek ini menggunakan 2 buah pompa, 2 buah tangki air, 1 sebagai tangki sebagai tangki underground dan 1 lagi sebagai tangki tower. Menggunakan WLC (water level control) untuk mengontrol hidup mati pompa berdasarkan ketinggian air pada tangki tower. Menggunakan Relay Change over untuk merubah pompa on duty secara otomatis.selain itu membantu mengontrol tandon penampung air secara otomatis sehingga tidak akan terjadi keadaan tangki penampung air yang meluap atau kosong dan menjaga stabilitas distribusi air pada tangki penampung air. adalah:

Yang dikaji dari alat yang akan dibuat

1. Sistem perpipaan supplai air bersih.

2. Sistem elektrikal kontrol pompa

3.Troubleshooting sistem elektrikal kontrol pompa.

4.Maintenance and repair pompa.

\section{METODOLOGI}

Metodologi penelitian ini dibagi dalam dua rancangan, yaitu rancangan mekanikal dan elektrikal.

\section{Rancangan Mekanikal.}

Gambar 1 menampilkan gambar mekanik yang akan dibuat. Terdiri atas 2 tangki, tangki pertama sebagai tangki underground, sebagai penampungan air dari PDAM atau air bawah tanah. Sedangkan tangki kedua, adalah sebagai tangki tower, tangki persediaan air yang akan diistribusikan ke outlet-outlet secara gravitasi. Sebelum pompa terpasang pipa suction dengan foot valve, yang berfungsi untuk menjaga air dalam pipa suction selalu ada. Kalau tidak ada footvalve, pompa tidak akan bisa memompakan air ke tower, karena pipa suctionkondisi tidak terisi air. Setiap pompa akan terisi gate valve dan check valve. Check valve berfungsi untuk menuntup instalasi pipa pada saat pompa memerlukan perbaikan, sedangkan check valve berfungsi untuk menutup aliran jika pompa sebelahnya sedang on duty. Header berfungsi untuk mengumpulkan air sebelum menuju ke tangki tower.

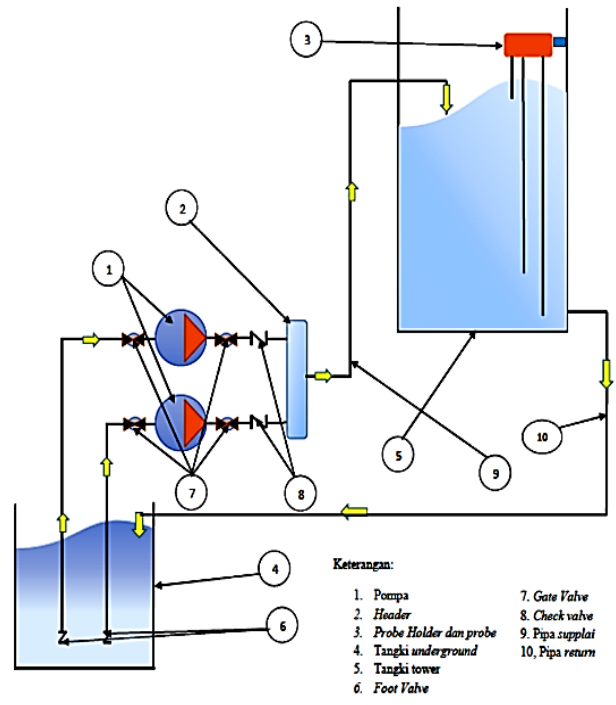

Gambar 1. Mekanikal Perpipaan

Cara kerja instalasi ini adalah, 2 buah pompa yang akan on duty bergantian. Saat Pompa 1 on duty, pompa 1 akan mengalikan air ke tangki tower dari tangki underground. Pada saat tangki tower penuh, dengan memasang sensor WLC (Water level Control), Pompa 1 akan automatis mati. Selanjutnya Pompa 2 akan automatis sebagai on duty. Pada saat sensor WLC mengindikasikan tangki tower berkurang airnya karena air mengalir ke tangki underground, Pompa 2 akan automatis hidup mengalirkan air ke tangki tower. Demikian selanjutnya pompa 1 dan pompa 2 akan bergantian hidupnya.

\section{Rancangan Elektrikal}

Gambar 2 Instalasi elektrikal terdiri dari instalasi daya dan kontrol, setiap instalasi daya terdiri dari MCB 16 A, kontaktor dan thermal overload sebagai pengaman. Pompa tidak akan bisa hidup jika kondisi air tower sudah penuh, karena adanya WLC sebagai pengontrol level air di tower. Pompa bisa dihidupkan secara manual ataupun automatis sepanjang level air tower tidak penuh. Dengan memutar selector switch masing-masing Pompa, manual, off dan automatis. Jika dipilih mode manual, maka kita perlu menekan tombol Push button On untuk menghidupkan pompa. Jika pilih mode automatis maka pompa akan hidup secara auto. Relay change over akan memindahkan on duty pompa secara automatis, setelah tangki tower penuh. Saat pompa 1 on duty memindahkan air dari tangki underground ke tangki tower, begitu tangki tower penuh, pompa 1 mati, relay change over 
akan langsung memindahkan pompa on duty dari pompa 1 ke pompa 2 .

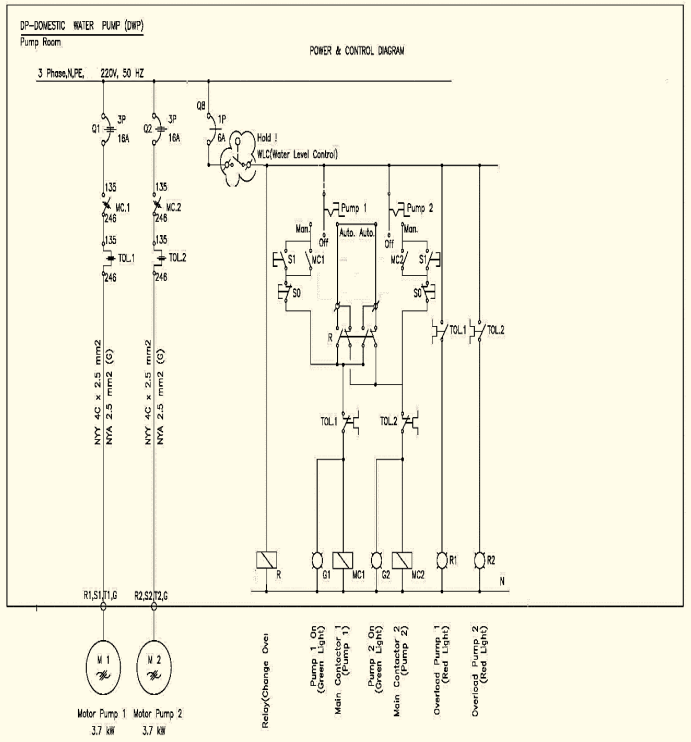

Gambar 2. Skemaelektrikal

Lampu-lampu indikator akan hidup sesuai dengan kondisi operasional. Jika pompa1 hidup, maka lampu pompa 1 akan lampu hijau pompa 1 akan hidup. Jika terjadi masalah pada pompa1, maka lampu merah pompa 1 akan hidup.

\section{HASIL DAN PEMBAHASAN}

Hasil penelitian ini berupa Produk Simulasi Kontrol 2 pompa supplay air bersih menggunakan Relay Change over dan Floatless Level Switch. Produk ini terbagi menjadi dua bagian, yaitu:

1. Bagian mekanikal

Berupa instalasi pemipaan dari pipa dari underground tank (foot valve, bagian valve pengisian, pipa suction kemudian pompa), pemipaan tower tank (check valve, valve dan discharge pipe).

\section{Bagian Elektrikal}

Berupa bagian kelistrikan dan control, bagian ini terdiri dari MCB, Kontaktor, Thermal Overload, switch over relay, floatless level switch dan kabel.

1. Bagian Mekanikal

a. Bagian Underground Tank

Bagian ini terdiri dari tangki air, pipa suction, foot valve pada ujung pipa suction dan bagian pengisian air pipa suction (Gambar 3).
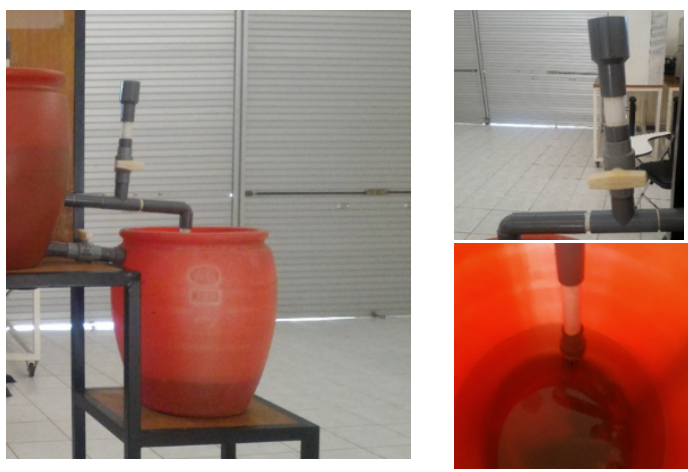

Gambar 3. Underground tank

-Foot valve berfungsi untuk menahan air pada pipa suction supaya air dipipa suction tidak kosong. Jika pipa suction tidak berisi air, tetapi berisi udara, maka pompa sentrifugal tidak akan bekerja (tidak bisa menghisap air). Pada beberapa pompa, udara yang berisi pada pipa suction akan dihisap oleh pompa keluar dan akhirnya air akan bisa terpompa. Untuk pompa ini, pipa suction harus terisi air.

-Valve pengisian air, bagian ini berfungsi untuk mengisi pipa suction dengan air, setelah terisi air, valve harus dalam kondisi tertutup.

-Tangki air, berfungsi sebagai tempat air yang akan dipompa.

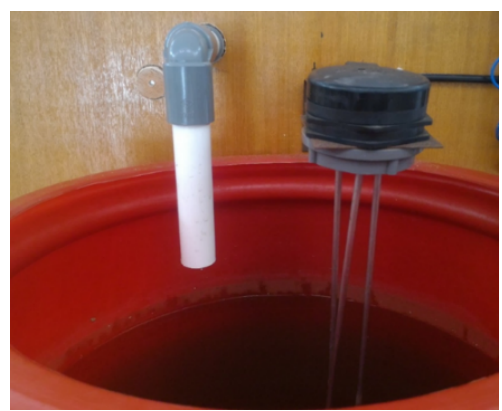

Gambar 4. Tower tank

\section{b. Bagian Tower Tank}

Bagian ini (Gambar 4) terdiri tangki air, pipa discharge pompa, probe holder dan probe.

-Pipa discharge ini merupakan pipa keluar dari pompa yang berasal dari tangki underground menuju ke tower.

-Probe holder merupakan tempat mengikat probe sebagai sensor level air.

-Probe adalah berupa 3 buah batang besi stainless steel yang berbeda-beda panjangnya yang berfungsi untuk sensor ketinggian air.

Probe no. 1 berfungsi sebagai cummon.

Probe no. 2 berfungsi sebagai sensor low level. Jika level air tidak lagi menyentuh probeno. 2, 
maka pompa akan hidup/on, karena air sudah mencapai level terendah.

Probe no. 3 berfungsi sebagai sensor upper level. Jika air sudah menyentuh probe no.3 makan pompa akan mati/off. karena sudah mencapai level tertinggi yang diizinkan

\section{c. Pompa Air}

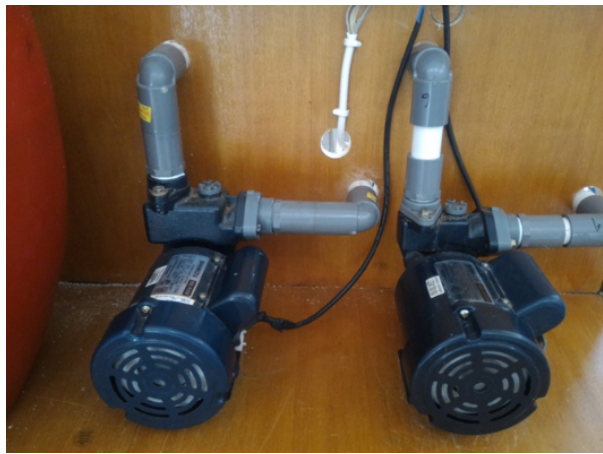

Gambar 5. Pompa

Pompa (Gambar 5) ini bertugas memindahkan air dari tangki underground ke tangki tower. On duty 2 buah pompa ini bergantian. Jika yang on duty pertama Pompa 1. Saat tangki tower low level Pompa 1 akan on, dan bertugas memenuhi tangki tower, setelah tangki tower penuh, Pompa 1 akan off. Selanjutnya yang on duty adalah Pompa 2 secara otomatis jika tangki tower mencapai low level. Setelah Pompa 2 on duty dan tangki tower sudah mencapai Upper Level dan Pompa 2 akan off. Setelah itu Pompa 1 akan on duty, demikian seterusnya.

\section{Bagian Elektrikal}

Secara keseluruhan rangkaian elektrikal adalah seperti ditunjukkan Gambar 6.

Rangkaian elektrikal terbagi menjadi 2, yaitu rangkaian power yang merupakan rangkaian power ke beban utama, yaitu pompa. Dan rangkaian kontrol yang menjaga sistem kontrol 2 pompa ini berjalan sesuai dengan rencana.

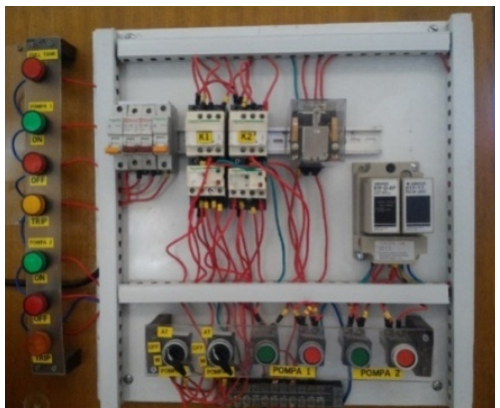

Gambar 6. Sistem elektrikal
Bagian-bagian dari elektrikal adalah:

1. MCB (mini circuit breaker), seperti pada Gambar 7.

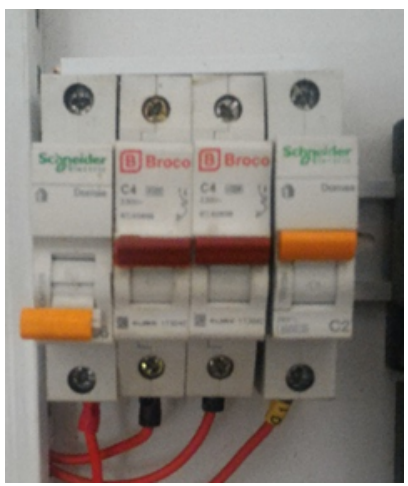

Gambar 7. MCB

Ada 4 MCB terpasang, MCB 1 paling kiri berfungsi sebagai main $\mathrm{MCB}, \mathrm{MCB}$ utama yang menerima power dari luar dan mendistribusikan ke MCB lainnya. MCB 2 sebagai poweruntuk Pompa 1, MCB 3 sebagai Power untuk Pompa 2 dan MCB 2 paling kanan berfungsi untuk MCB untuk Kontrol.

\section{Kontaktor dan Thermal overload}

Gambar 8 menunjukkan kontaktor dan Thermal Overload. Kontaktor berfungsi meneruskan Power dari MCB ke Pompa 1 dan 2 berdasarkan perintah kontrol. Sedangkan thermal overload adalah berfungsi sebagai pengaman pompa Jika pompa mengalami masalah, dan mengakibatkan motor pompa panas dan overload, maka thermal overload ini akan memutus arus yang ke Kontaktor. Sehingga pompa yang bersalah akan off.

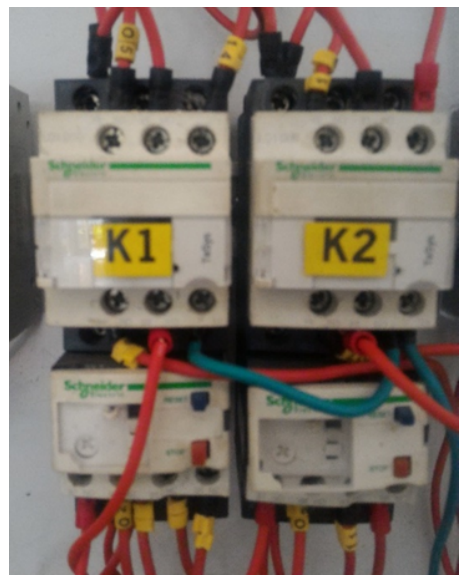

Gambar 8. Kontaktor dan Thermal Overload 
3. Switch over relay

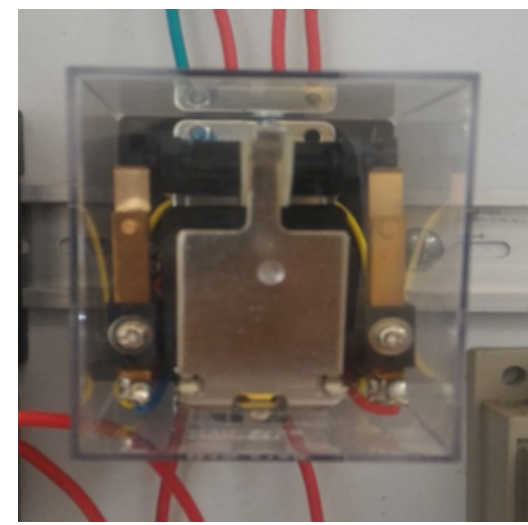

Gambar 9. Swich over relay

Relay ini (Gambar 9) berfungsi untuk memindahkan pompa yang on duty secara otomatis. Setelah Pompa 1 on duty dan off, selanjutnya Pompa 2 akan menjadi yang on duty.

\section{Floatless Level Switch probe}

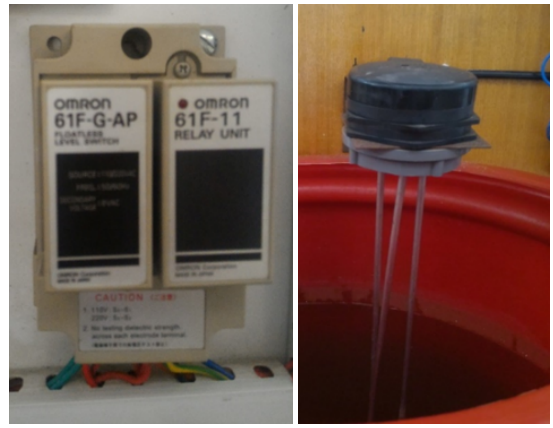

Gambar 10. Floatless level switch dan probe

Bagian ini (Gambar 10) berfungsi untuk mengatur level air ditangki tower. Sehingga tower tidak akan pernah over flow selama bagian berfungsi dengan baik. FLS ini akan dihubungkan dengan probe yang berfungsi sebagai sensor level air.

5. Switch Kontrol Manual - Automatis

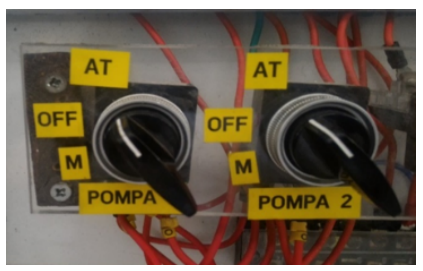

Gambar 11. Switch kontrol manual-automatis

Bagian ini (Gambar 11) berfungsi untuk operator memilih apakah pompa ini dijalankan secara automatis atau manual. Jika mode Automatis dipilih, maka pompa akan beroperasi dengan automatis, artinya pompa akan hidup dan mati berdasarkan level air dalam tangki tower. Dan akan bergantian on duty-nya.

Jika dipilih mode manual, maka pompa hidup berdasarkan operator yang memilih apakah Pompa1 atau Pompa 2 yang akan dihidupkan dengan menekan push botton switch yang ada.

\section{Push button switch.}

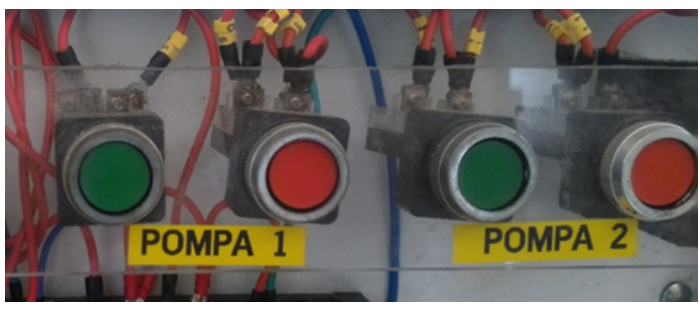

Gambar 12.Push button switch

Bagian ini (Gambar 12) diperlukan jika mode manual yang dipilih operator. Ini digunakan jika salah satu perlu perawatan dan mode aoutomatis tidak bisa dijalankan, maka pompa lainnya bisa dihidupkan secara manual untuk mengisi tangki tower. Untuk menghidupkan pompa ditekan tombol berwarna hijau, jika ingin mematikan ditekan tombol merah.

7. Lampu Indikator.

Bagian ini (Gambar 13) untuk menunjukkan status sistem ini. Lampu teratas menunjukkan tangki tower sudah sudah penuh, pompa tidak akan hidup, walaupun mode manual atau automatis yang dipilih.

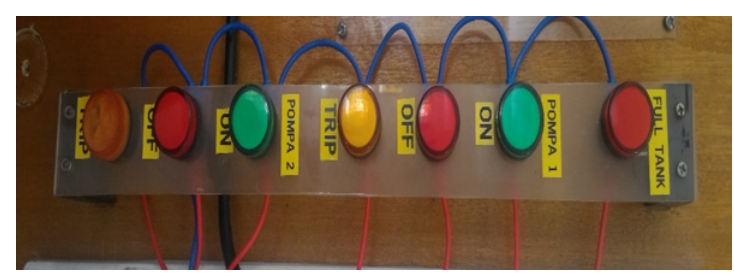

Gambar 13. Lampu indikator

Dibawahnya ada status Pompa 1, jika Pompa 1 On atau Off lampu tersebut menyala, jika Pompa 1 mengalami masalah, lampu Trip yang akan menyala. 
8. Uji Alat Simulasi

Alat simulasi ini sudah selesai dirakit, langkah selanjutnya adalah menguji kehandalan dari system kontrolnya, apakah pompa yang terpasang tersebut bisa bergantian hidupnya untuk melayani tangki tower.

Untuk pengujian ini, valve(Gambar 14) yang terpasang diantara tangki, dibuka setengah, sehingga air yang dipompa ke tangki tower tidak diam di tangki tower, tapi langsung sebagian menuju tangki underground.

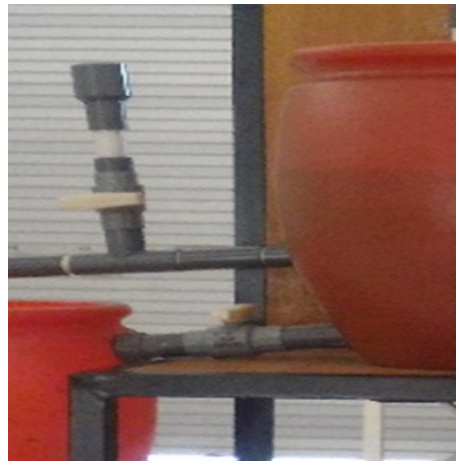

Gambar 14. Valve Penghubung antar Tangki

Langkah pengujian.

1. Isi pipa suction dengan air. Dengan cara buka valve pengisian pipa suction. Isi sampai pipa suction semua terisi air, buka baut yang ada di

2. Pompa bagian atas, untuk membuang udara yang terperangkap dalam pipa suction.

3. Selector switchdalam posisi off semua

4. Hubungkan kabel power alat simulasi dengan power yang ada disekitar alat simulasi.

5. Hidupkan semua MCB yang ada.

6. Selector switch rubah ke posisi automatis. Alat simulasi akan hidup dengan sendirinya sesuai kondisi level air dalam tangki tower.

7. Lampu indikator akan hidup sesuai kondisi alat simulasi bekerja. Jika Pompa 1 On, maka lampu indokator Pompa 1 On hidup. Jika Pompa 1 Off, maka lampu indicator Pompa 1 Off akan hidup.

Dengan kondisi valve penghubung tangki tower dan tangki underground terbuka setengah, maka pompa hidup bergantian, seperti Gambar 15.

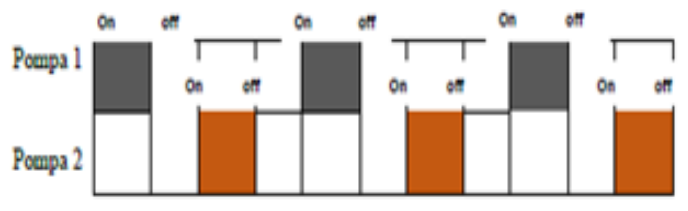

Gambar 15.Grafik kerja dua pompa alat simulasi

\section{KESIMPULAN}

Alat Simulasi Kontrol 2 pompa supplay air bersih (Gambar 16) menggunakan Relay Change over dan Floatless Level Switch saat diuji Pompa 1 dan Pompa 2 bekerja secara bergantian sesuai dengan yang direncanakan. Setelah Pompa 1 bekerja memenuhi tangki tower, Pompa 1 akan stand by, Pompa 2 yang bekerja saat level tangki tower mencapai low level.

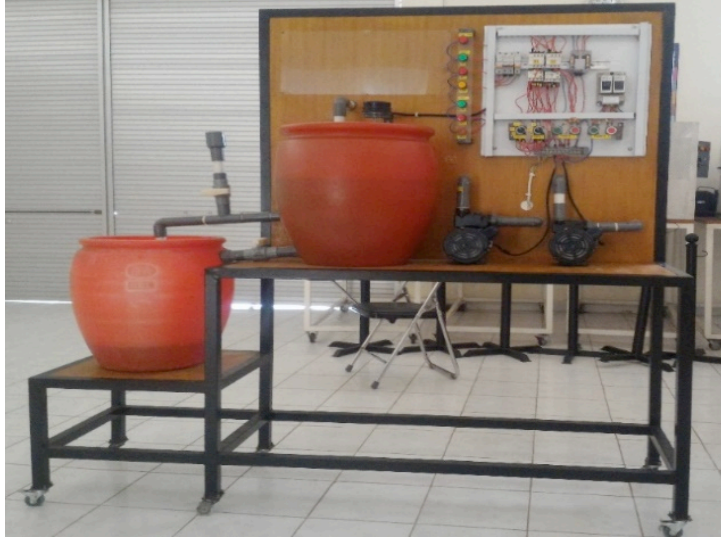

Gambar 16. Tampak depan Simulasi

Alat Simulasi Kontrol 2 pompa supplay air bersih menggunakan relay change over dan floatless level switch, siap untuk dipakai praktek pada mata kuliah praktek Utility Gedung dan BAS.

\section{SARAN}

Beberapa hal yang bisa kami sampaikan sebagai saran-saran, yaitu:Baca buku panduan praktek modul dan pahami sebelum melakukan praktek.Usahan berhatihati dalam melakukan praktek dengan alat ini, jangan menyentuh kabel atau konektor yang tidak berisolasi, karena bagian tersebut mengandung aliran listrik dan menyebabkan dampak yang berbahaya.Karena ada air dan listrik, usahakan tangan tidak dalam keadaan kena air/basah untuk menghidupkan modul.

\section{UCAPAN TERIMA KASIH}

Kami mengucapkan banyak terima kasih kepada P3M Politeknik Negeri Bali, karena sudah mensupport dan membiayai penelitian berupa alat simulasi untuk praktek mahasiswaini lewat Dana Dipa Tahun Anggaran 2017.

\section{DAFTAR PUSTAKA}

[1] D. Adiantoro, Perancangan Otomatisasi Kontrol Pompa Sirkulasi Air Dingin Gedung Media Energy Supply(Mes) IRM, 
Hasil-hasil Penelitian EBN Tahun 2009, Jakarta, 2009.

[2] M. R. Harahap, "Rangkaian Dan Pengujian Sistem Kontrol Aliran Air Dengan Mikrokontroler Atmega8535 dan Pemrograman C," Universitas Sumatera Utara, Medan, 2015.

[3] Omron, "Manual WLC OMRON 61FG3," Bangkok, 2016.

[4] Omron, "Manual relay swich over Omron GQ-212S," Bangkok, 2015.

[5] A. Taftazani, Darsonodan Sudjatmoko, "Studi Kemampuan Akselerator (PIXE) Untuk Pemantauan Kualitas Lingkungan Hidup," Prosiding Pertemuan dan Presentasi Ilmiah Teknologi Akselerator dan Aplikasinya, Yogyakarta, hal. 7-14, 2002. 